\title{
O cine-eu, ou como o planeta passou a girar em torno do meu umbigo
}

\section{Cine-I, or how the world started revolving around me}

Marcius Freire ${ }^{1}$ 


\section{Resumo}

Com o esgarçamento dos valores que serviam de referência ao desenvolvimento humano e ao aprimoramento de sua existência no mundo, o indivíduo viu-se desnorteado ideologicamente, desestabilizado em suas convicções e inseguro quanto ao seu papel na sociedade. O documentário contemporâneo, fazendo eco a esse estado de coisas, passou a gestar um número cada vez maior de micro-histórias pessoais que, algumas vezes, podem reverberar processos sociais ou históricos mais amplos.

Palavras-chave

Documentário, autobiografia, autoficção, narcisismo.

\section{Abstract}

With the disintegration of values which served as references to human development and welfare in the world, one may have found themselves ideologically confused, adrift in their convictions and unsure about their role in society. Thereby, as an echo of this state of affairs, more and more personal micro-stories and dramas have been thriving in the context of contemporary documentary film. This phenomenon can occasionally amplify or reflect upon wider social or historical processes.

\section{Keywords}

Documentary, autobiography, self-fiction, narcissism. 
O presente artigo retoma um tema que já foi explorado de forma sucinta em duas ocasiões diferentes, ambas nos encontros da Socine ${ }^{2}$. Na primeira, nos debruçamos sobre filmes de dispositivos e filmes autobiográficos, mas enfatizando, de fato, apenas os primeiros. Na segunda, atacamos, efetivamente, a questão dos artefatos audiovisuais em que o realizador volta a objetiva para si. No entanto, naquela ocasião, nossos objetos foram os filmes de arte ou filmes de artista, muitos dos quais se consubstanciavam bem mais como espécies de duplos, de registros de performances ou de outras manifestações efêmeras que precisavam, para se tornarem perenes, serem postos em um suporte persistente, no caso, o suporte fílmico. Agora, nossa intenção é verificar o filme em primeira pessoa que se propõe a ser uma construção sobre algo que não está dado no mundo histórico e que não é, tampouco, uma forma de registro de uma obra de arte que poderia existir independentemente do filme. Ao contrário, ele pretende se desenvolver nesse mundo como um percurso, como uma busca (parafraseando Jean-Claude Bernardet), como uma autobiografia, como um retrato ou um autorretrato em que o protagonista é o próprio realizador ou com ele se associa para a produção do artefato.

De acordo com aquilo que anunciamos no resumo, partimos do pressuposto de que, com o esgarçamento dos valores que serviam de referência ao desenvolvimento humano e ao aprimoramento de sua existência no mundo, o indivíduo viu-se desnorteado ideologicamente, desestabilizado em suas convicções e inseguro quanto ao seu papel na sociedade. O campo do documentário contemporâneo, fazendo eco a esse estado de coisas, passou a germinar um número cada vez maior de micro-histórias pessoais que, algumas vezes, podem reverberar processos sociais ou históricos mais amplos, outras nem tanto.

De par com esta interpretação para a prática cinematográfica atual, existe uma outra que não pode ser negligenciada. Com efeito, é preciso levar em conta 
que a vulgarização do suporte digital, sua miniaturização e o seu barateamento tornaram a incursão nos liames da realização fílmica extremamente acessível. Como corolário, temos uma proliferação jamais vista de obras audiovisuais sendo produzidas. Ademais, a sociedade contemporânea, com seus incontáveis instrumentos de registro domésticos e o pernicioso hábito/vício do selfie, fez de todos e de cada um que deles dispõe um cineasta/fotógrafo de ocasião. Logo, a tentação de colocar em cena a si mesmo é enorme, o que levou alguém a nomear os amantes dessa prática de "Dorian Gray modernos"3.

Uma terceira variável merece ser mencionada. Ela diz respeito à hierarquização da significância das diversas fases do processo criativo. Melhor dizendo, dos dois principais momentos que conformam a obra: a sua feitura e a sua exposição ao público. Aqui, o documentário vai ao encontro das artes plásticas que, já há algum tempo, abandonou seus suportes tradicionais, levando o artista a transformar seu próprio corpo em suporte para a sua arte. Para além da body art, são inúmeros os exemplos de intervenções de toda sorte a que os corpos são submetidos como forma de subversão dos cânones da arte figurativa e, mesmo, da arte moderna de fatura tradicional. O que importa não é mais a exposição de uma peça, de um objeto ou mesmo de uma instalação, mas de um processo a que o espectador assiste. Tal processo pode ou não ser filmado, mas sua criação tem como objetivo a sua fruição ao vivo.

Podemos ver nesse conjunto de traços distintivos da arte moderna alguns dos sintomas que conformariam, segundo Jean-François Lyotard, a pós-modernidade:

Na sociedade pós-industrial, pós-moderna, a grande narrativa perdeu a sua credibilidade. Podemos ver nesse declínio das narrativas uma consequência da expansão das tecnologias a partir da segunda guerra mundial, que deslocou a ênfase da ação dos seus fins para os seus meios; ou, ainda, da reorganização do capitalismo liberal avançado após seu recuo sob a três deles concordavam que sua geração era mais narcísica do que a geração precedente - um admirável e honesto reconhecimento de um retrato muito pouco lisonjeiro" (TWENGE; CAMPBELL, 2009, p. ix, tradução nossa). Todas as traduções deste artigo são nossas. 
proteção do keynesianismo durante os anos 1930-1960, renovação que eliminou a alternativa comunista e que valorizou o prazer individual dos bens e dos serviços. (LYOTARD, 1979, p. 63)

\section{Alguns brotos do rizoma "eu"}

O cinema documentário de que aqui tratamos também se preocupa mais em mostrar como é realizado do que em se mostrar acabado. Em sua grande maioria, o processo criativo é a própria razão de ser do filme. É ele que serve de fio condutor e o seu realizador é quem puxa esse fio à vista do espectador.

Dir-se-ia que essa substituição da obra acabada pela obra em processo nada mais é do que um dos sintomas daquilo que Paul Valéry (1944, p. 6) afirmou: "Pode acontecer que sejamos levados a considerar com mais complacência, e mesmo com mais paixão, a ação que faz, do que a coisa feita".

Se considerarmos que Valéry (que viveu entre 1871 e 1945) fez essa observação em 1937 e levarmos em conta todas as inovações introduzidas nos processos criativos das artes visuais desde então, seremos obrigados a admitir que algumas de nossas premissas teriam de ser relativizadas.

Evidentemente, Valéry estava se referindo mais à literatura, poeta que era. No entanto, se remontarmos o fio do tempo à procura do primeiro processo de criação literária em construção vamos encontrar Santo Agostinho. Este possui as credenciais que Ihe conferem a história de, ao descrever as dores de seu arrependimento e sua consequente conversão ao cristianismo, ainda no século IV, ter escrito com suas Confissões a primeira autobiografia formalmente conhecida ao se confessar a Deus (alguns falam das Confissões de Rousseau, mas estas só viriam a ser escritas no século XVIII).

Coube a Montaigne, já no século XVI e, segundo alguns, antecipando Freud no desejo de se autoconhecer, perguntar-se: "quem sou eu?". Assim, a propósito de seus Ensaios, declarou que era ele próprio a matéria de seu livro. Durante dez anos ele vai, então, buscar recontar a sua vida interior. E, aqui também, construir sua narrativa à vista do leitor. 
Em relação à pintura, será apenas no século XV que Botticelli, em seu quadro $A$ adoração dos magos (1475) (aqui, de alguma forma antecipando As meninas, de Velázquez), vai se inserir na cena por ele pintada dirigindo o seu olhar para aquele que admira o seu quadro. No entanto, é bom sublinhar que já em 1433 Van Eyck se pintara em um quadro intitulado O homem com o turbante vermelho. Van Eyck serviu de modelo para o tal homem.

Contudo, vai ser mesmo na Renascença, quando o homem se insere no centro do universo, deixando de lado as crenças na magia e no sobrenatural como sustentáculo de seu estar no mundo, características da Idade Média, que os autorretratos efetivamente começam a ocupar espaço nos ateliers dos pintores. É importante acrescentar, no entanto, que um avanço tecnológico também propiciou a eclosão do autorretrato na renascença: a invenção do espelho plano de vidro, que possibilitava um reflexo muito mais apurado de quem nele se admirava. Dentre os pintores que se dedicaram à arte do cultivo da própria imagem, os flamengos e os holandeses foram os mais profícuos. Rembrandt pintou mais de noventa autorretratos, entre 1627 e 1669 (não havia necessidade de modelo).

Mas, antes disso, entre 1500 e 1512, o pintor alemão Albrecht Dürer, foi um grande pintor de autorretratos. Contam os historiadores da arte que ele foi o primeiro a pintar - na verdade desenhar - um autorretrato nu da história. Chama a atenção nesse desenho a riqueza dos detalhes daquilo que constitui, efetivamente, um nu: a genitália. Diferentemente do David de Michelangelo, em que a genitália é a de uma criança, aqui trata-se da de um homem adulto por volta de seus 35 anos, idade aproximada do pintor à época em que produziu o desenho. A obra encontra-se hoje no Schlossmuseum Linz [Museu do Castelo] em Weimar e, ao que parece, não foi realizada para ser exposta. Dürer é tido como aquele que trouxe o narcisismo para a arte pictórica, tamanho é o volume de autorretratos que deixou. Mas este é assunto para outro artigo.

Esta nossa pequena digressão pelas artes pictóricas tem o papel de demonstrar que, como dissemos, a nossa premissa precisa ser nuançada. 
Ou seja, que se mostrar, se autoapresentar em "micro-histórias pessoais", como dissemos a respeito do documentário contemporâneo, ou cultivar a própria imagem em representações imagéticas ou outras, não é apanágio da contemporaneidade. Esta apenas disponibilizou meios mais eficientes para fazê-lo. E, a cada vez que a tecnologia produz avanços nos instrumentos de registro do mundo histórico, a representação do homem e de sua subjetividade adquire novos contornos. Portanto, como vimos rapidamente, o "eu" como matéria-prima da arte já vem da noite dos tempos. Não propriamente do tempo cronológico, mas dos tempos da Idade Média. Parafraseando o velho Marx, a história (no nosso caso, a história da arte) não se repete, mas está sempre gaguejando.

\section{O cine-eu}

Todos sabemos que, no cinema, a máquina de registrar o movimento das coisas do mundo já nasce praticamente olhando para os seus próprios inventores. Ou seja, a presença do "eu" criador, do demiurgo, já consta da primeira projeção oficial do cinematógrafo no Salon indien du Grand Café, ocorrida em 28 dezembro de 1895. De fato, dos dez filmes que compunham a mostra dos Lumière, eles próprios são mostrados em pelo menos dois deles, Poissons rouges e Le repas de bébé4.

Tal fato não é propriamente uma première na história das invenções. Santos Dumont voou em seus protoaviões; o mesmo fizeram os irmãos Wright. Mas, o que nos interessa aqui é a relação que, logo nos seus primórdios, começa a se estabelecer entre o filmador e o filmado ou, dizendo de outra forma, entre aquele que se arma desse instrumento de registro das coisas do mundo e aquilo que ele escolhe desse mundo para ser filmado. Mais especificamente, o cerne do nosso interesse é quando essas duas instâncias se confundem. 
Voltando aos primórdios, Méliès, presente na primeira exibição e potencial comprador do engenho, logo que atingiu o seu intento se colocou diante das objetivas e passou a ser ele próprio o objeto do olhar de sua câmera. Assim como Van Gogh cortou uma orelha em 1888 e pintou o seu famoso autorretrato com curativo em 1889 - ao todo ele pintou 35 autorretratos, alguns com o famoso curativo na orelha -, Méliès vai cortar sua cabeça e fazer outras estripulias para a sua objetiva. Porém, diferentemente do autotorturado Van Gogh, Méliès, o mago das imagens em movimento, queria divertir se divertindo. Mas, para tanto, não hesitava em se mostrar ele próprio em cena, em se multiplicar através de seus truques e em contracenar consigo mesmo explodindo a própria cabeça.

Em que pese este começo autocentrado - pelo menos do lado europeu do Atlântico ( ão nos consta que Thomas A. Edison tenha servido de modelo para suas fitas kinetoscópicas) -, o filme propriamente autobiográfico só vai desabrochar e merecer este epíteto - mesmo que este Ihe tenha sido dado muito depois no final dos anos 1950, começo dos anos 1960. Não vamos retraçar essa história, pois não é esse o nosso objetivo, mas apenas mencionar um nome que deve ser sempre lembrado quando se trata de filme autobiográfico ou filme em primeira pessoa: Stan Brackhage. Foi ele que, na virada dos anos 1950 para os anos 1960, começa a filmar sua vida privada nas montanhas do Colorado. Rusgas em família, nascimento de um filho, enterro do cão de estimação etc.

Aqui, haveria necessidade de uma tipologia do filme em primeira pessoa ou autobiográfico, o que, evidentemente, está fora de questão. Vamos, portanto, nos ater àquilo que, pedindo emprestado o conceito à literatura, de onde aliás saíram os outros, vamos chamar de autoficção. Para tanto, e como introdução ao tema, escolhemos um filme do realizador suíço de nascimento, mas belga de adoção e filho de imigrantes poloneses, Boris Lehman. 


\title{
Autobiografia ou autoficção?
}

Antes, porém, vamos ao conceito de autoficção. Tal conceito foi forjado por Serge Doubrovsky, na contracapa de seu livro Fils (palavra ambígua, que tanto quer dizer filho quanto fios no plural), publicado em 1977.

Em um texto de 2007, Doubrovsky (2007, p. 61) procura esclarecer o neologismo que criou:

\begin{abstract}
Eu quero então precisar um pouco o meu pensamento. O que quer dizer esta frase: "ficção, de fatos e de acontecimentos estritamente reais" utilizada na quarta capa de Fils? Parece-me que existe aí uma contradição nos termos já que, segundo Philippe Lejeune, e eu sou um "lejeunista" puro e duro, ele separa, no Pacto autobiográfico, "eu abaixo assinado", o critério essencial da homonímia e o ato de referência, a "cópia fiel", ou a "cópia autenticada". [...] Existe então, segundo Philippe Lejeune e Paul John Eakin ${ }^{5}$ uma oposição radical entre a autobiografia, concebida dessa maneira, e o romance, que repousa sobre um pacto de ficcionalização, mesmo que se fale correntemente de "romance autobiográfico". Aos olhos de Philippe Lejeune, o romance autobiográfico não constitui, no entanto, um gênero em si. Ainda nos dias de hoje alguns críticos confundem romance autobiográfico, autoficção, narrativa pessoal. [...] Há uma tergiversação em torno da palavra, mas eu acredito que Philipe Lejeune disse com justeza: é imperativo que o nome próprio do escritor seja o nome do personagem. É tudo ou nada, não há solução intermediária.
\end{abstract}

Ora, não vamos entrar, nestas breves linhas, na discussão sobre a necessidade imperativa de haver homonímia entre o autor, o narrador e o personagem para que, de fato, exista autobiografia na literatura. Mas, sabemos que isso é possível. Não obstante, é lícito nos perguntarmos se o mesmo pode acontecer no cinema. Na literatura é necessário um pacto, um acordo de leitura entre o leitor e o autor do livro. Não à toa, Lejeune intitulou seu livro de $O$ pacto autobiográfico. Eu sou o autor do livro, o seu personagem central sou eu, temos o mesmo nome e sou eu que narro a minha própria história. Você, leitor, deve acreditar nisso. Tudo que você vai encontrar nestas páginas eu vivi de fato. Cabe então a esse leitor 
imaginar os personagens em cena, os lugares que frequentaram, os eventos por eles vividos etc.

Como é possível fazer o mesmo no corpo a corpo - melhor seria dizer no face a face - com um filme? Se, segundo Lejeune, na relação com o texto escrito o leitor é obrigado a fazer um "esforço de imaginação" para reconstituir aquele "esforço de memória" primordial, realizado pelo autor na reconstituição de seu passado, como é possível fazer isso no suporte fílmico?

Ora, um primeiro traço distintivo do filme é que a crença de que os acontecimentos narrados efetivamente aconteceram com aquele que narra não é necessária, uma vez que, em boa parte dos casos, os dois personagens se confundam. Tal é o caso de Tarnation (2003), em que o diretor Jonathan Caouette monta registros por ele realizados durante mais de vinte anos, nos mais variados suportes, como Super 8, VHS e fotografias, tendo ele mesmo como figura principal dos registros. Já em Los rubios (2003), de Albertina Carri, a realizadora empreende um processo de busca pelos rastros dos seus pais desaparecidos durante a ditadura do general Jorge Rafael Videla na Argentina. Mas, além de representar o seu papel de filha de um dos milhares de militantes eliminados sem deixar rastro pelos militares, Albertina também se mostra como a diretora de um filme que se constrói a partir dessa busca, inclusive dirigindo a atriz Analia Couceyro, que a representa em algumas sequências.

Os formatos de que se servem os realizadores para fazerem filmes sobre si mesmos, sobre passagens das suas vidas ou mesmo para se envolverem com fatos que Ihes são exteriores e que procuram (retratar) são múltiplos e diversificados ${ }^{6}$. fazer a narração em primeira pessoa, envolve a vida dos seus pais na trama política, fazendo-os parte da História. Segundo o jornalista Astier Basílio (2019), em matéria publicado no jornal O Estado de São Paulo, e conforme indicado no próprio título do artigo, os acontecimentos expostos são pura invencionice. 


\section{Boris Lehman e a autoficção fílmica}

Tomemos como exemplo de realizações documentais em primeira pessoa a obra do belga Boris Lehman. Nascido na Suíça em 1944 de pais poloneses que se estabeleceram na Bélgica, mas que tiveram de fugir do país quando os nazistas o invadiram. Foram então para a neutra Suíça e lá nasceu Boris. Ele viveu apenas um ano em Lausanne, pois, com o fim da guerra, os pais voltaram para a Bélgica.

Boris Lehman começou a fazer seus filmes no começo dos anos 1960 e filma desde os 14 anos, além de fazer fotografias. Em mais de cinquenta anos de atividades, dirigiu curtas e longas-metragens em Super 8 e 16 mm, somando mais de quatrocentos títulos. Suas realizações transitam por todas as modalidades do filme em primeira pessoa. Sua vida se confunde a tal ponto com suas obras que ele afirma não fazer seus filmes, mas ser feito por eles.

Se para Serge Doubrovsky, como vimos, o criador do conceito de "autoficção" em literatura, esta se define como "ficção, de fatos e de acontecimentos estritamente reais", encontram-se autoficções na obra de Lehman; se na autobiografia é necessário que o autor, o narrador e o personagem se confundam, como quer Philippe Lejeune, grande parte dos filmes de Lehman é autobiográfica; se, para Michel Beaujour (1980, p. 9), contrariamente ao autobiógrafo, o autorretratista afirma "eu não vou Ihes contar o que eu fiz, mas vou lhes dizer quem eu sou", Boris Lehman realizou autorretratos; se acompanharmos Langford e West (1999, p. 11) quando afirmam que "o diário balança entre a escrita literária e a escrita histórica, entre a espontaneidade e a reportagem, entre si mesmo e eventos, entre o público e o privado", encontram-se muitos cine-diários na filmografia de Boris Lehman.

Certamente, em razão das múltiplas estratégias fílmicas de que lança mão, o cineasta declara que "[seus] filmes não são longos nem curtos. Não são documentários nem ficções. Eles são sempre o mesmo filme, um filme único, um cinejornal escrito no dia a dia, em pequenos pedaços, com migalhas acumuladas" (LEHMAN, 1993). E continua: "O que é o cinema de Boris Lehman? Talvez seja um cinema que procura justamente uma definição, que hesita entre 
documentário etnográfico, filme científico, ficção experimental, filme terapêutico e filme autobiográfico" (LEHMAN, 1993).

Entre 1983 e 1991, Lehman realiza Babel, lettres à mes amis restés en Belgique, filme de 380 minutos em que os preparativos de uma viagem ao México são os protagonistas por excelência. Como típico artefato de fatura ensaística, Babel se constrói diante dos olhos do espectador. Como em todos os seus filmes, Boris Lehman representa o seu próprio papel e, como tal, seu nome é Boris Lehman. Na verdade, não se trata de representar um papel, mas de filmar seu dia a dia. Se a sua vida é banal, Lehman cria eventos, projetos, inventa fatos e vai vivê-los diante da câmera. É esse o caso de sua viagem ao México, que se traduz no mote para a realização de Babel. No filme, a vida do realizador desfila diante dos nossos olhos em toda a sua banalidade até o ponto de inflexão que é a ideia de fazer a viagem ao México. Tal viagem só começa a ser mencionada aos quarenta minutos de filme. Por que o México? Não sabe muito bem, mas vai à procura do Tarahumaras, em busca de Antonin Artaud.

Mas, até que essa viagem aconteça, o espectador é confrontado com os encontros e desencontros do realizador; com as saídas com os amigos - sobretudo amigas -, para quem ele conta do seu projeto. Em bares, restaurantes, parques, toda sorte de lugar, Boris se expõe e expõe os outros. Quando não está em companhia de alguém, são suas deambulações pelas ruas de Bruxelas, seus percursos e entrevistas que nos são expostos. Mesmo o seu banheiro, onde lava os pés para nós - promovidos a voyeurs de ocasião pelo personagem/realizador é objeto da nossa mirada.

Essa exposição de si, essa manifestação de narcisismo primário que define o estado precoce em que a criança investe toda a sua libido em si mesma, levou o crítico Michel Cieutat, da revista Positif publicada no verão de 1988, a fazer o seguinte comentário sobre um filme do mesmo realizador apresentado no $16^{\circ}$ Festival do Filme de Estrasburgo: "Muet comme une carpe (1987), do belga Boris Lehman, média metragem de narcisismo judaico e cinematográfico 
algo invasivo" (CIEUTAT, 1988, p. 100). Seja lá o que ele tenha querido dizer com "narcisismo judaico".

Como podemos ver, a marca do "eu" está presente em todas as obras do realizador. A tal ponto que, segundo ele mesmo declara: "um amigo me disse que eu organizava a minha vida para filmá-la. Não, minha vida se organiza independentemente da minha vontade, e eu nela vou buscar a matéria dos meus filmes. É verdade que eu sempre me encantei - às vezes me apavorei com aquilo que acontecia comigo" (LEHMAN, 2011, p. 16).

Mas, como explicar tal nível de relação íntima entre ele e suas criações? O que levaria um artista a fazer de sua própria pessoa o objeto de sua criação? Claro que os artefatos fílmicos de Lehman não constituem o exemplo mais extremado dessa imbricação criador-criatura, notadamente se pensarmos nas performances de uma Marina Abramović ${ }^{7}$ ou nas cirurgias plásticas de Mireille Suzanne Francette Porte, as quais transformam o seu corpo e são transmitidas ao vivo ${ }^{8}$. No entanto, em ambos os casos, o "evento" artístico tem lugar e hora marcados para acontecer e o público/espectador é convidado a assistir, muitas vezes pagando para isso. Mesmo que as duas artistas levem para casa nos próprios corpos - as marcas de sua "obra". Já o cinema de Lehman, como vimos há pouco, só pode existir se o fluxo do seu tempo no planeta - por óbvio, partes desse fluxo - acontecer diante da objetiva de sua câmera. É lícito nos perguntarmos o que leva um indivíduo a fazer de seu estar no mundo o objeto de suas criações.

Praticante de uma arte cujo suporte é o seu próprio corpo, a performer Abramović, autodenominada "avó da performance", sempre se preocupou em registrar as suas ações. Da fotografia às imagens em movimento, boa parte das suas realizações foi desenvolvida tendo em vista sua preservação. Uma de suas últimas apresentações teve lugar no MoMa, em 2010, e consistiu em permanecer ao longo de sete horas sentada em uma cadeira, olhando fixamente para alguém que havia enfrentado uma longa fila para poder desfrutar deste momento único de poder encará-la durante alguns minutos. O evento, intitulado The artist is present, durou três meses e deu origem a um filme homônimo, dirigido por Matthew Akers. 
Buscar responder a essa questão é uma tarefa árdua que nos levaria pensamos - a enveredar por áreas como a Psicanálise, por exemplo. Ainda não temos hipóteses a esse respeito. Mas, nas nossas prospecções iniciais, deparamonos com o postulado da crítica Jacqueline Aubenas, publicado na Cinémas: revue d'études cinématographiques, publicação da Universidade de Montreal, em seu número do outono de 1997, intitulado "Le soleil septentrion".

Ela se pergunta:

Seria o conceito de melancolia um dos traços profundos do cinema belga, uma vez que a sua simples evocação reúne os mais importantes nomes de algumas gerações de cineastas? Esse conceito não permitiria, no entanto, dividir o cinema desse país em diferentes correntes ou escolas. Estes que ele - o conceito - reúne são obstinadamente singulares. A melancolia, no entanto, se torna um dos temas reveladores de uma identidade belga que se define pelo desconforto, a interrogação e a incerteza. (AUBENAS, 1997, p. 47)

Depois de expor as originalidades da formação da Bélgica enquanto país, o que só veio a ocorrer em 1830 ao se separar dos Países Baixos, a autora discorre sobre aquela que seria a segunda vertente de seu postulado: a "memória", ou como ela prefere, o "dever de memória", para não confundir com a "memória" no sentido de "lembrar". Segundo ela, diante de figuras como:

Hitler, Pol Pot, os genocidas ruandeses [...] diante de uma tal paisagem de exterminação e de desolação profunda, como não ser melancólico? Ora, essa ansiedade, esse pavor estão inscritos na própria carne de cineastas desse país, como Chantal Ackerman, Samy Szlingerbaum e Boris Lehman. (AUBENAS, 1997, p. 50)

Evidentemente, os três cineastas citados têm contas a acertar com o primeiro dos tiranos citado e o holocausto por ele orquestrado.

A terceira vertente de sua hipótese é a questão da identidade, mas, evidentemente, não vamos tratar dela aqui. Gostaríamos apenas de, a título de conclusão provisória, citar uma afirmação do próprio Lehman, que vem corroborar 
o viés da memória citado pela autora. Diz ele, apropriando-se, mais uma vez, de Rimbaud:

Eu gostaria de prestar uma última homenagem ao cinema que me fez nascer uma segunda vez para a existência. Então, um filme sobre uma época, e um filme sobre uma vida (a minha), mas também sobre a vida dos outros, sobre todas as vidas. Desta vez "Je c'est tout le monde". (LEHMAN, 2011, p. 20)

\section{Referências}

AUBENAS, J. Le soleil septentrion. Cinémas: Revue d'Études Cinématographiques, Montreal, v. 8, n. 1-2, p. 47-65, 1997.

BASÍLIO, A. O fantástico mundo de Petra: como a cineasta inventou um passado clandestino para seus pais. O Estado de S. Paulo, São Paulo, 11 jul. 2019.

BEAUJOUR, M. Miroirs d'encre: rhétorique de l'autoportrait. Paris: Seuil, 1980.

CIEUTAT, M. XVIe Festival du film de Strasbourg. Positif, Paris, n. 329-330, p. 99-100, 1988.

DOUBROVSKY, S. Fils. Paris: Éditions Galilée, 1977.

DOUBROVSKY, S. Les points sur les «i». In: JEANNELLE, J.-L.; VIOLLET, C. (dir.). Genèse et autofiction. Louvain-la-Neuve: Academia-Bruylant, 2007. v. 6, p. 5365. (Coleção Au coeur des textes).

LANGFORD, P.; WEST, R. Introduction: diaries and margins. In: LANGFORD, P.; WEST, R. (ed.). Marginal voices, marginal forms: diaries in European literature and history. Amsterdam: Rodopi, 1999. p. 6-21. 
LEHMAN, B. Les films que j'ai faits et qui n'existent pas. Art Press, Paris, n. 14, 1993. Disponível em: https://bit.ly/2Vlgsxb. Acesso em: 5 out. 2019.

LEHMAN, B. Babel: lettre à mes amis restés en Belgique. Bruxelas: Éditions Yellow Now, 2011.

LEJEUNE, P. Pour l'autobiographie. Paris: Seuil, 1998.

LYOTARD, J.-F. La condition postmoderne. Paris: Les Éditions de Minuit, 1979.

TWENGE, J. M.; CAMPBELL, W. K. The narcissism epidemic: living in the Age of Entitlement. Nova York: Atria Paperback, 2009.

VALÉRY, P. Leçon inaugurale du cours de poétique au Collège de France. In: VALÉRY, P. Variété V. Paris: Gallimard, 1944. p. 295-322.

submetido em: 19 ago. 2019 | aprovado em: 07 set. 2019 